\title{
Higher-Education Ecosystem Construction and Innovative Talents Cultivating
}

\author{
Ziye Wang1, Qingying Zhang2 \\ ${ }^{1}$ Wuhan Sports University, Wuhan, China \\ ${ }^{2}$ School of Logistics Engineering, Wuhan University of Technology, Wuhan, China \\ Email: kathy8899@126.com
}

How to cite this paper: Wang, Z.Y. and Zhang, Q.Y. (2019) Higher-Education Ecosystem Construction and Innovative Talents Cultivating. Open Journal of Social Sciences, 7, 146-153. https://doi.org/10.4236/jss.2019.73011

Received: December 19, 2018

Accepted: March 10, 2019

Published: March 13, 2019

\begin{abstract}
In the era of a knowledge economy, lots of requirements, such as innovative talents cultivation, life-long education, are put forward for the higher education, with the object of endowing the students the ability of succeeding, integrating, and disseminating knowledge, which depends on the establishment of a sustainable ecological environment and a practical platform provided for the students. The paper finds out the concept and connotation of educational ecology, analyzes the rules or principles of high-education ecosystem, discusses the creation of a balanced ecological environment and innovation platform, and summarizes the working and experience of our educational project.
\end{abstract}

\section{Keywords}

Ecosystem, Higher-Education, Innovation, Creation Platform

\section{Basic Requirements of Talents Cultivating}

In the era of knowledge economy, lots of demands, such as life-long education, innovative talents cultivation, are put forward for the higher education [1]. The object of our education, i.e. the revolutionary talents are requested to have the ability of succeeding, integrating, and disseminating knowledge, which depends on the establishment of a sustainable ecological environment and a practical platform provided for the students, especially for the excellent and active ones [2].

It is very effective and necessary to establish a benign circle of scientific research ecosystem, build an open innovation platform for college students based on theoretical and practical research, and integrate the cultivation of innovation consciousness and ability into the whole process of education. 


\section{Ecosystem of High-Education}

\subsection{Concept of Educational Ecology}

Educational ecology originated from the ecological study of human behavior. Ashby, an American educator, put forward the concept of "ecology of higher education" in 1966. Gremin, dean of Columbia Normal College, proposed the term "educational ecology" in 1977, defined the method of educational ecology as "to examine the links between educational institutions and structures and the broader societies that sustain them and are affected by them". He regarded education as an organic, complex and unified system, in which all the factors (schools and other educators) in the educational ecosystem are organically linked, which in turn shows consistency and contradiction, balance and imbalance dynamically. It is a new concept that promotes education development ecologically from the view of world outlook, sense of worth, communication, balance, and dynamic perspective to investigate education problems and then carry on education research theoretically and practically in a brand new ecological way [3].

\subsection{Connotation of Educational Ecology}

Educational ecosystem refers to the unit of educational ecology composed of education, other natural ecosystems and social ecosystems through material, information circulation and capacity exchange in a certain space-time range. It is necessary to explore the factors and their relations in the process of education, recognizes the various elements of education and the ecological niche and characteristics of education in the natural and social systems, and grasps the vitality and endowment of educational activities in the unification of structure and function, so as to promote a sustained and harmonious development of education in an all-around, systemic and natural way.

The essence of educational ecology is roughly expressed as "two relations", which refers to the man-man, and man-society relation, "three environments", i.e. social education environment, school education environment, and family education environment; "four factors" means psychological factor, environmental factor, political factor, and economic factor, while "five demands" include physiological demand, psychological demand, aesthetic demand, talent grow-up demand and innovation demand.

\subsection{Characters of High Education Ecosystem}

Higher education is ordinarily thought as the interactions of various internal factors of education system and the exchange between education and external environment (society) in the forms of substance, energy and information [4].

In a university ecosystem, there are three basic value subjects: educator, educatee, and society, centered on the human factor.

The basic contents of the system are to pursue advanced knowledge, study in depth, gain professional proficiency, search solution for various problems, and 
to explore, survey and discover new things.

An ideal university ought to get a comprehensive development by keeping balance between teaching and researching, general education and professional education, natural science and literae humaniores, on-campus and off-campus affairs, as well as nationalization and internationalization.

The relationship between higher education and social environment has a similar internal mechanism with that between biology and biology, biology and environment, which is composed of main body, individual, environment and other elements. The element influences and restricts each other while the value of each element is embodied through others, so it is a typical social ecosystem. In this ecological system, the educator teaches the educatee in the school (in fact, the exchange of material and energy information within the system) or through social practice (i.e., the exchange of material and energy information between systems) to coordinate the balanced development of the elements of the system and maintain the stability of the system, so as to promote the sustainable development of the higher education system steadily and continuously.

From the point of view of ecology, one of the basic characteristics of higher education as an ecosystem is its overall relevance, which is manifested in the overall connection between the educational ecosystem and the social system and the internal elements of the educational ecosystem [5]. Another important basic feature is the dynamic balance, which is manifested in the education and social environment. A harmonious symbiotic relationship formed by the interaction between them, and the development of the internal structure of education itself tends to be harmonious and balanced. Ideal higher education is hopeful maintain a natural balance between the internal and external environment of the education system. In order to, therefore, follow the path of ecological development, higher education is asked to follow the basic natural principles, basic principles and moral norms.

\section{Fundamental Principles of High-Education Ecosystem}

Constructing and improving the ecosystem of higher education is not only a new educational concept, but also a natural, harmonious, open and innovative development model of modern higher education. It attaches great importance to and highlights the overall function and cultivates ecological people, regards educational activities as an organic dynamic whole, and concentrates the spirit of affinity and integration in every organic factor and link, finally forming a unified educational ecological whole.

The construction of higher education ecosystem needs to follow some basic rules.

\subsection{Principles of Ecological Process}

Ecological process principle is a mandatory or orderly rule since the university is a cultural ecosystem where basic ecological process has to be respected exceptionally. It is an imperative principle to maintain the integrity, hierarchy, pur- 
pose and environmental adaptability of the system from the perspective of management, and to coordinate various ecological factors in order to build a healthy ecosystem and improve the efficiency of school running.

\subsection{Combination of Education and Morality}

It is an advocacy principle to combine different forms of education with different moral realms and make rational use of educational resources so as to improve the overall quality of the educated and promote the stability and prosperity of the education system.

\subsection{Principles of Ecology Chain}

In an ecological system, nutrition relationship between individual organisms often appears to be a complex net structure rather than a simple liner form, and then an ecology chain with complicated architecture is took shape. Unlike a nature's food chain, educational ecology chain is not only a relationship of energy conveying and receiving, spreading out and uptaking, but also a complex relation of knowledge flow, in the forms of horizontal, vertical and cross-cutting mixed, according to the stages and the characters of education. It has rarely been discussed since the contents and the relations are fairly intricate and difficult to be described qualitatively. A workable proposition is to take the ecology chain as a gray system, and to probe it qualitatively, quantitatively and dynamically by means of modern science and technology.

\subsection{Principles of Purposiveness}

Purposiveness is momentous for a system and the requirements are usually met through the processes of feedback, self-organization, and self-adjusting. So does an education system. The better it does in the self-organization and self-adjusting, the more accurate the disparity is discovered from the feedback, and the more perfect it satisfies the requirement of the system. This has been confirmed by system science.

\subsection{Other Principles}

Besides the laws and principles mentioned above, lots of standards and rules, e.g. the restriction factor law, tolerance law and the most appropriate principle, flower pot effect, educational niche principle, educational ecological chain law, educational rhythm, social cohesion and Ali principle, group dynamics, relationship of groups, integrity effect and margin effect of educational ecosystem, are all available to analyze the system and its characteristics.

\section{High-Education Development from the Perspective of Ecologism}

\subsection{Current Problems in the High Educational Ecosystem}

From the perspective of ecological structure, there are still some contradictions 
and imbalances in the hierarchical structure, school system structure, type structure, curriculum structure and teacher structure of higher education in China. As for the teacher structure, for example, it is known that highly educated teachers has joined, especially in the team of classroom teaching, while the experimental instructors are ordinarily insufficient in level, ability and education background. Once the in-service degree-earning experimenters have received their doctorates, they are immediately transferred to the teaching faculty series. It is a common problem to attach importance to classroom and neglect experiment. As a result, the due role of practice has not been fully played, students have poor hands-on ability and have low skills. Even if they get high marks in the exam, they may not really have mastered the knowledge of the subject. The imbalance between theory and practice is an anti-ecological phenomenon.

The so-called "normalization" and "standardization" of teaching management have also curbed the development of educational ecology to a certain extent. The teaching process is asked to be kept strictly correspondence with the schedule designed before, and the examination paper is to be corrected and marked according to the standard answer without any fraction of difference. Even if the examination is open-book one, the grading point has to be given rigidly. If the teacher chooses thesis writing as the evaluation of the students' final grade which is more effective to assess student's divergent thinking and comprehensive ability, he/she must submit a score criterion of the final grade with more than 20 evaluating indicators and write down the reason for the mark for each paper to the management department. Under such a great pressure, teachers have to give up the valid but tough way but take the easier one. Thus, student-oriented ecological teaching idea goes back to knowledge-based way, which is actually an ecological regression.

\subsection{Sustainable Development of High-Education Ecosystem}

High-education situates is in a multi-dimensional ecological network, whose ecological environment is composed of ecological, natural, social, cultural, economic, physical, psychological, as well as basic education, vocational education, adult education and other education ecological factors. To achieve a sustainable development, high-education has to be balanced with the ecological environment, and with internal environment of the human beings.

1) Creating a Balanced Ecological Environment

A balanced development of the ecological environment of high education ought to be created, which includes the following three aspects:

- An ecological environment for students growing up

A sustainable development of education ties directly not only to the overall progress, but the continuous advance of the individuals. Education is a complicated systematic project, which needs to be well-designed and managed under the guidance of system theory and the principles according to the actual status, the natural instincts and growth pattern of the students. 
- An ecological environment for teachers' improvement

"Teacher" is a crucial link of "ecological chain" of education. The overall level of teachers' quality affects fatefully the development of the educational ecological environment, and cultivation of creative talents. For teachers themselves, the impactful self-improvement and ego integrity are necessary and able to be completed in an ecological environment. As the saying goes that to give students a glass of water, teachers should have a bucket of water, our education ecological environment is definitely to provide teachers and then the students, with the constant sources of water.

- An ecological environment for university's independent development

All the work of universities ought to be carried out based on the ecological development principles and concepts. In consideration of sustainable development of education, not only the hardware, or the structure of a university is attached importance ordinarily, but the software-the sustainable environment of cultivating talents must be paid more attention. Human development is the process of overall harmony. Psychologists point out that man is an unfinished animal, who completes himself only by an unremittingly study and constantly practice.

From a broad perspective of education and its ecological development, to convert the traditional "closed" to the "open" mode, to combine and share the resources with public and the society, have been proved to be the useful ways to establish ecological education environment. MOOC (Massive Open Online Courses) boomed recent years have played a significant role in education and its ecological improvement.

2) Constructing an Open Platform for Innovation

High marks and low abilities are not uncommon problems for Chinese college students. A university, in its true sense, is not only a campus where imparts and learns knowledge and respects existing knowledge, but also a free palace where full of researching, exploration, practicing, questioning, criticizing, controversy, and, negating. Without research and exploration, without expression and debate, without questioning and meditation, there will be no real university spirit. Constructing an open innovation platform provides a stage full of ecological atmosphere for students.

The cultivation of students' innovative ability has become a focus of work in the construction of ecological campus. It is necessary to reform the teaching system, curriculum setting, practical links, and the organization of activities in and out of class [6]. In addition to the "innovative training", "basic intensive training" and "ability development training" offered in summer are all proved to be the useful means. Equally important is that to encourage teachers to actively carry out teaching reform and scientific research practice, integrate creative education into the teaching process, communicate in-class and out-of-class classes, and actively create an ecological campus atmosphere that encourages innovation. 
Moreover, organizing students to participate in various disciplines competitions, scientific and technological innovation, as well as social practice activities, and establishing a long-term mechanism and incentive mechanism to stimulate the enthusiasm of teachers and students to participate in activities including entrepreneurship are all confirmed to be available [7]. Another useful way is to equip undergraduates with tutors, so that as many students as possible can accept the direct guidance of teachers, participate in various scientific research activities, and effectively improve their practical and innovative abilities.

In practice, we put cultivation of innovative capability as the focus of ecological campus building by a series of reforms, such as re-construction of the education system and model of instruction, re-design of curriculum, re-arrangement of practical training, etc. Some brand new practice steps are schemed, including "innovative training", "the basis of intensive training", and "capacity development training". Furthermore, teachers are encouraged to carry out research and practice of education reform, to blend innovative training into teaching. The students have more incentives to take part in various creative and practical activities, e.g. discipline competition, social practice, project research, investigation and study, and paper writing.

\section{Conclusion}

The study of educational ecosystem pays attention to the whole process and all the elements of education and their relationship. Constructing a good educational ecosystem and an open innovation platform, creating an ecological environment in which students grow freely, teachers improve themselves and schools develop independently, are effective ways to train more high-quality innovative talents.

\section{Conflicts of Interest}

The authors declare no conflicts of interest regarding the publication of this paper.

\section{References}

[1] Sharp Phillip, A. (2014) Meeting Global Challenges: Discovery and Innovation through Convergence. Science, 346, 1468-1471.

https://doi.org/10.1126/science.aaa3192

[2] Liu, Z., Fei, J., Wang, F., et al. (2012) Study on Higher Education Service Quality Based on Student Perception. International Journal of Modern Education \& Computer Science, 2, 22-27. https://doi.org/10.5815/ijeme.2012.04.04

[3] Quan, S.J. and Wang, Y.L. (2017) Study on the Structure and Characteristics of Higher Education Ecosystem in Hong Kong. Journal of Higher Education Management, 11, 117-124.

[4] Vaishali, S. and Dwivedi, S.K. (2015) Two Way Question Classification in Higher Education Domain. International Journal of Modern Education \& Computer Science, 9, 59-65. 
[5] Xu, T. and Yan, L. (2017) Research on Ecosystem Model and Elements of Innovation and Entrepreneurship Education in International Higher Education: A Case Study of MIT. Journal of Distance Education, 4, 15-29.

[6] Zhang, S., Gang, W., Zhang, S., et al. (2013) The Thought and Practice in Teaching Reform of "Soil Mechanics". International Journal of Modern Education \& Computer Science, 1, 55-59. https://doi.org/10.5815/ijeme.2013.01.10

[7] Hills, G.E. (1988) Variations in University Entrepreneurship Education: An Empirical Study of an Evolving Field. Journal of Business Venturing, 2, 109-122.

https://doi.org/10.1016/0883-9026(88)90021-3 